\title{
Attaching and effacing lesions in vivo and adhesion to tissue culture cells of Vero-cytotoxin-producing Escherichia coli belonging to serogroups 05 and 0103
}

\author{
Graham A. Hall, ${ }^{*}$ C. Richard Dorn,${ }^{2} \dagger$ Neil Chanter, ${ }^{1}$ Sylvia M. Scotland, ${ }^{2}$ \\ HENRY R. SMITH ${ }^{2}$ and BERNARD ROWE ${ }^{2}$ \\ ${ }^{1}$ Agricultural and Food Research Council, Institute for Animal Health, Compton Laboratory, Compton, Newbury, \\ Berkshire RG16 ONN, UK \\ ${ }^{2}$ Division of Enteric Pathogens, Central Public Health Laboratory, Colindale Avenue, London NW9 5HT, UK
}

(Received 8 November 1989; accepted 16 January 1990)

\begin{abstract}
Certain isolates of Escherichia coli from humans and animals with enteric disease attach to enterocytes and cause 'attaching and effacing' (AE) lesions. E. coli strain S22-1, serotype O103: H2, isolated from a child with diarrhoea, contained two plasmids; one of these (pDEP12) hybridized with the CVD419 DNA probe derived from a plasmid found in $E$. coli $0157: H 7$ and associated with expression of fimbriae and ability to adhere to Intestine 407 cells. Strain S102-9, serotype 05: $\mathrm{H}^{-}$, isolated from a calf with dysentery, contained six plasmids, one of which also hybridized with the CVD419 probe. Loss of pDEP12 coincided with reduced adhesion to HEp-2 or Intestine 407 cells cultured in vitro; reintroduction of this plasmid restored adhesiveness. Loss of the plasmid in strain S102-9 that hybridized with the CVD419 probe did not cause a decrease in adhesion. Accumulations of actin were seen in vitro in the fluorescence actin staining (FAS) test of strains S22-1, S102-9 and their derivatives, irrespective of the plasmid content of these strains or the prevalence of attached bacteria. Strain S22-1 and its plasmidless derivative caused AE lesions of equal severity in experimentally infected gnotobiotic piglets; piglets inoculated with an isolate from a healthy human or pig did not develop these lesions. These results indicate that the CVD419 probe is not specific for genes conferring the ability to adhere to HEp-2 or Intestine 407 cells by these $E$. coli and that the adhesins detected in vitro, or plasmid-encoded properties, are not required for strain S22-1 to cause AE lesions in gnotobiotic pigs or to cause the accumulation of actin in cells in vitro.
\end{abstract}

\section{Introduction}

Certain isolates of Escherichia coli from human and animal disease produce cytotoxins which act on Vero cells (Konowalchuk et al., 1977); they produce one or two distinct Vero cytotoxins, VT1 and VT2 (Scotland et al., 1985b), also called SLT I and SLT II (Strockbine et al., 1986). Some $E$. coli strains, including Vero-cytotoxinproducing $E$. coli (VTEC) attach to the apical surfaces of enterocytes in their natural host and in gnotobiotic pigs where they produce 'attaching and effacing' (AE) lesions (Moon et al., 1983; Tzipori et al., 1986; Hall et al., 1988);

† Present address: Department of Veterinary Preventive Medicine, Ohio State University, 1900 Coffey Road, Columbus, Ohio 43210, USA.

Abbreviations : AE, attaching and effacing; EAF, EPEC adherence factor; EPEC, enteropathogenic E. coli; FAS, fluorescence actin staining; SLT, Shiga-like toxin; VT, Vero cytotoxin; VTEC, Verocytotoxin-producing $E$. coli. they also possess attachment mechanisms detectable by in vitro tests (Karch et al., 1987; Sherman et al., 1987; Dorn et al., 1989). Serotypes of particular interest which possess these characteristics are $0157: \mathrm{H} 7$, the predominant isolate in human outbreaks of haemorrhagic colitis (Riley et al., 1983; Pai et al., 1984; Smith et al., 1987), and serotype $\mathrm{O} 5: \mathrm{H}^{-}$, isolated from calves with dysentery (Chanter et al., 1984; Hall et al., 1985; Moxley \& Francis, 1986).

The toxins are not the cause of AE lesions (Tzipori et al., 1987; Hall et al., 1988), although they are thought to be involved in the pathogenesis of disease (Fontaine et al., 1988); the role of attachment mechanisms detectable in vitro is not clear. The $\mathrm{O} 5 \mathrm{:H}^{-}$calf strain (S102-9) and three human VTEC strains (serotypes O55:H7, $\mathrm{O} 103: \mathrm{H} 2$ and $\left.\mathrm{O} 111 \mathrm{ac}: \mathrm{H}^{-}\right)$possess the ability to adhere to HEp-2 cells and Intestine 407 cells in vitro (Dorn et al., 1989). These strains did not hybridize with the enteropathogenic $E$. coli (EPEC) adherence factor (EAF) DNA 
probe which identifies plasmid genes necessary for expression of adhesion to HEp-2 cells (Baldini et al., 1986; Nataro et al., 1985) and in human volunteers (Levine et al., 1985). Karch et al. (1987) reported that 13 of 14 strains of $E$. coli of serotype $0157: \mathrm{H} 7$, isolated from haemorrhagic colitis or haemolytic uraemic syndrome patients adhered to Intestine 407 cells but not to HEp-2 cells. These strains possessed a $60 \mathrm{MDa}$ plasmid which hybridized with a probe, designated CVD419, prepared from the $60 \mathrm{MDa}$ plasmid in strain 933, serotype O157:H7 (Levine et al., 1987) and they were seen to be fimbriated by electron microscopy. When these strains were cured of the plasmid, they failed to express fimbriae and lost the ability to adhere to Intestine 407 cells, suggesting a pathogenic role for the plasmid; subsequently, it was shown that the $60 \mathrm{MDa}$ plasmid was not essential for expression of virulence by E. coli $\mathrm{O} 157: \mathrm{H} 7$ in piglets (Tzipori et al., 1987, 1989). The calf strain (S102-9) and a human diarrhoeal isolate S22-1, serotype O103:H2, hybridized with the CVD419 probe and they adhered in a localized manner to HEp-2 and Intestine 407 cells (Dorn et al., 1989). The purposes of this study were to compare adhesion of non-O157:H7 VTEC in vivo and in vitro and to examine the roles of the CVD419-hybridizing plasmid, and of other plasmids and adhesins in their pathogenicity for gnotobiotic piglets.

\section{Methods}

Bacterial strains. Strain S22-1, serotype $0103: \mathrm{H} 2$, was isolated from a child hospitalized with diarrhoea in Canada (Gurwith \& Williams, 1977). Strain S102-9, serotype $\mathrm{O} 5: \mathrm{H}^{-}$, was isolated from a calf with enteritis from a herd with this illness in England (Chanter $e$ t al., 1984). Strain E1541/68, serotype O154:H4, was isolated from a healthy human and strain E53181, serotype O8:H9, was isolated from a healthy pig; both were used as controls for in vitro and in vivo experiments. Additional information about the properties of these four wild-type strains is provided in Table 1.

S22-1 carries two plasmids designated pDEP12 and pDEP13. Derivatives lacking pDEP12, pDEP13 or both plasmids, as listed in Table 1, were obtained. Strain S22-1-5B was isolated following heat treatment of S22-1 at $48{ }^{\circ} \mathrm{C}$ for $18 \mathrm{~h}$. CVD419-probe-negative colonies were tested and one of these, S22-1-5B, only carried pDEP13. Toobtain strain 62R64, the F-Tc plasmid was transferred into S22-1; tetracycline-resistant transconjugants showed loss of pDEP12 resulting from incompatibility of the two plasmids. Loss of tetracycline resistance, selected by replica plating, resulted in isolation of $62 \mathrm{R} 64$ that carried pDEP13 alone. To produce strain 62R70, the plasmid pMR5 that carries the ampicillin-resistance transposon Tn801, was transferred into S22-1. pMR5 is temperature-sensitive for replication and can be used for transposition of $\mathrm{Tn} 801$ to other replicons (Robinson et al., 1980). One of the resulting transconjugants carried pDEP12 and pMR5 but $\mathrm{pDEP} 13$ had been lost. Transposition of Tn 801 to $\mathrm{pDEP} 12$ resulted in strain 62R41 carrying pDEP12::Tn801. Loss of ampicillin resistance, detected by replica plating, yielded strain $62 R 70$ that still carried pDEP12. Strain 62R75 was derived by transfer of plasmid F-Tc into 62R41 and this resulted in loss of pDEP12::Tn801. Loss of F-Tc yielded strain $62 R 75$ that had no plasmids. Strain $62 R 140$ was obtained after plasmid pDEP12::Tn801 was introduced into $62 \mathrm{R} 75$ by transformation.

Strain S102-9 had six plasmid bands ranging in size from $<4$ to $59 \mathrm{MDa}$ (Table 1). Transfer of the F-Tc plasmid into S102-9 resulted in loss of a $46 \mathrm{MDa}$ plasmid that hybridized with the CVD419 probe; an isolate lacking this plasmid was designated $62 \mathrm{R} 15$.

DNA probes and hybridization procedure. Methods used to produce the VT1 and CVD419 DNA probes and the hybridization procedures have been described (Dorn et al., 1989).

Plasmid DNA preparation, transformation, agarose gel electrophoresis and Southern hybridization. Plasmid DNA was prepared by the alkaline extraction method (Birnboim \& Doly, 1979). Purified plasmid DNA of pDEP12::Tn801 was prepared by the alkaline-SDS lysis method followed by centrifugation in caesium chloride/ethidium bromide density gradients. Transformation with plasmid DNA was done by the method of Kushner (1978). The plasmid DNA extracts were run on $0.6 \%(\mathrm{w} / \mathrm{v})$ agarose gels in TB buffer containing $89 \mathrm{mM}$-Tris base, 89 mu-boric acid and 2.5 mM-EDTA (Willshaw et al., 1979). Each strain was run at least twice. Each observed plasmid band was assigned a corresponding molecular mass in $\mathrm{MDa}$ using seven molecular mass standards. After treatment of gels with $0.25 \mathrm{M}-\mathrm{HCl}$, plasmid DNA was transferred to Hybond N membrane by the method of Southern (1975) and hybridized with the CVD419 DNA probe as described above.

$H E p-2$ cell and Intestine 407 cell adherence. The wild-type strains and their derivative strains were tested for ability to adhere to HEp-2 cells and Intestine 407 cells in the presence of D-mannose by the method of Scotland et al. (1985a) using a $6 \mathrm{~h}$ incubation period. Bacterial adherence to these cells was classified according to Scaletsky et al. (1984). Localized adherence was observed and recorded as the percentage of HEp- 2 or Intestine 407 cells with 10 or more adherent bacteria. Strains which adhered to less than $10 \%$ of the HEp-2 or Intestine 407 cells were considered nonadherent for that cell line.

Fluorescence actin staining $(F A S)$ test. At the end of a $6 \mathrm{~h}$ adherence test HEp-2 cells were fixed in formalin $(3 \%, \mathrm{v} / \mathrm{v})$, washed, and treated to show accumulations of filamentous actin beneath adherent bacteria using the FAS test (Knutton et al., 1989). Briefly, cells were permeabilized with Triton X-100 $[0 \cdot 1 \%$ in phosphate-buffered saline [(PBS, NaCl, $8 \mathrm{~g} \mathrm{l}^{-1} ; \mathrm{KCl}, 0.2 \mathrm{~g} \mathrm{l}^{-1} ; \mathrm{Na}_{2} \mathrm{HPO}_{4}, 1.5 \mathrm{~g} \mathrm{l}^{-1} ; \mathrm{KH}_{2} \mathrm{PO}_{4}$, $\left.0.2 \mathrm{~g} \mathrm{l}^{-1}\right)$ ], and stained with fluorescein isothiocyanate-phalloidin $(5 \mu \mathrm{g}$ $\mathrm{ml}^{-1}$ in PBS; Sigma). The same stained cell monolayer was used to visualize adherent bacteria by phase contrast microscopy and concentrations of actin by incident light fluorescence.

Animals. Sixteen gnotobiotic piglets were obtained from two litters (Tavernor et al., 1971). At 3-d-old they were inoculated orally after the morning feed with $5 \mathrm{ml}$ sterilized canned milk (Carnation) containing $9.6 \times 10^{8}$ to $5.6 \times 10^{9}$ c.f.u. of $E$. coli grown on bovine blood agar at $37^{\circ} \mathrm{C}$ for $18 \mathrm{~h}$; piglets were inspected daily for signs of diarrhoea and killed $4 \mathrm{~d}$ later. The pathogenicity of each strain (S22-1, 62R75, E1541/68, E53181) was assessed by inoculating two piglets from each litter.

Bacteriology. To monitor for bacterial contaminants in gnotobiotic piglets faeces were collected prior to inoculation and at necropsy and cultured aerobically and anaerobically on blood agar and in thioglycollate broth. Two piglets inoculated with strain S22-1 were contaminated with a Streptococcus sp. at the time of necropsy. E. coli were enumerated as described previously (Chanter et al., 1984) in scrapings of mucosa from the ileum, caecum, colon and rectum, in faeces, and in intestinal contents. The mucosae were washed, scraped off with a glass slide and ground to make $10^{-1}$ suspensions in saline $(0.85 \% \mathrm{NaCl})$. Intestinal contents, faeces or mucosal suspensions $(1 \mathrm{~g})$ were serially diluted tenfold in saline and $0.1 \mathrm{ml}$ of appropriate dilutions spread onto MacConkey agar plates (Mackie \& MacCartney, 1953) in triplicate 
before incubation at $37^{\circ} \mathrm{C}$ for $18 \mathrm{~h}$. The numbers of $E$. coli per gram were enumerated according to the dilution of sample and the number of lactose-fermenting colonies per sample.

Necropsy procedures. Tissues for microscopy were removed under halothane anaesthesia (Fluothane, ICI). Short lengths (approximately $5 \mathrm{~cm}$ ) of small and large intestine were ligated to produce pairs of loops at three sites; adjacent to the ileocaecal junction (lower ileum) and in the proximal and distal halves of the spiral colon. One loop of each pair was filled with mercuric formol and the other with $3 \%(\mathrm{v} / \mathrm{v})$ glutaraldehyde in $0.1 \mathrm{M}$-sodium phosphate buffer. Samples from the blind end of the caecum and from the mid rectum were excised under anaesthesia and immersed in fixative. Piglets were killed by intracardiac injection of pentobarbitone sodium (Euthatal; RMB Animal Health). Ligated loops of intestine were removed and immersed in fixative. Brains were removed and immersed in mercuric formol together with samples of liver and kidney. Samples of intestinal walls and contents were saved for bacteriological examination. Fixed tissues were processed and examined for the presence of lesions by light microscopy and by scanning and transmission electron microscopy, as described previously (Hall et al., 1985).

Blocks of brain for histological examination were taken from the cerebellum, pons and cerebrum. All tissues were examined by light microscopy and all intestinal tissues by scanning electron microscopy. Intestinal tissues were selected from some piglets for examination by transmission electron microscopy to confirm the nature of lesions detected by light and scanning electron microscopy.

\section{Results}

Relationship between plasmids and adherence to cells in vitro

Strain S22-1 possessed two plasmids, pDEP12 and pDEP13, of which pDEP12 (44 MDa) hybridized with the CVD419 DNA probe; strain S102-9 possessed six plasmids, one of which (46 MDa) also hybridized with the CVD419 probe (Table 1); both isolates were adherent to cells in vitro. Loss of the CVD419. hybridizing plasmid (pDEP12) from S22-1 coincided with reduction in the ability of derivatives S22-1-5B, 62R64 and 62R75 to adhere to cells in vitro. Transformation of pDEP12 into the plasmidless derivative $62 \mathrm{R} 75$ produced a further derivative, 62R140, in which adherence to cells in vitro was restored. The derivative (62R70) which had lost pDEP13 but retained pDEP12 was still adherent. The derivative of S102-9, which lacked the CVD-419-hybridizing plasmid, was, however, as adherent as the parent strain or strain S22-1. Strains S22-1 and S102-9 were positive in the FAS test. All localized clusters of bacteria were associated with intense spots of fluorescence of the HEp-2 cells. Although these areas were related to attached bacteria, not every adherent bacterium was associated with fluorescence. Similar results were obtained with some strains by Knutton $e t$ al. (1989). All the derivatives of S22-1 and S102-9, even those which gave only rare clusters of adherent bacteria, were similarly positive in the FAS test and caused distinct concentrations of fluorescence (Table 1).

The control strains E1541/68 and E53181 possessed plasmids which did not hybridize with the CVD419 probe; these strains did not adhere to cells in vitro nor did they react in the FAS test.

\section{Clinical observations}

Liquid faeces were passed by piglets inoculated with strain S22-1 and at necropsy the perineum of these piglets was soiled with adherent faeces (Table 1). The faeces of piglets inoculated with strain $62 \mathrm{R} 75$ were soft or very soft, although they were liquid in one piglet on the third

Table 1. Properties of the strains

\begin{tabular}{|c|c|c|c|c|c|c|c|c|c|c|}
\hline \multirow[b]{3}{*}{ Strain } & \multirow[b]{3}{*}{ Serotype } & \multirow[b]{3}{*}{ Plasmids (MDa)* } & \multirow{2}{*}{\multicolumn{2}{|c|}{ DNA probes }} & \multicolumn{3}{|c|}{ Adherence tests } & \multirow{2}{*}{\multicolumn{3}{|c|}{ Effects on gnotobiotic piglets }} \\
\hline & & & & & & & & & & \\
\hline & & & VTI & CVD419 & HEp- $2 \dagger$ & $407 \dagger$ & FAS & Diarrhoea & Colonization & Lesions \\
\hline S22-1 & $\mathrm{O} 103: \mathrm{H} 2$ & pDEP13, pDEP12 & + & + & 22 & 25 & + & + & + & + \\
\hline S22-1-5B & $\mathrm{O} 103: \mathrm{H} 2$ & pDEP13 & + & - & 1 & 2 & + & NT & NT & NT \\
\hline 62R64 & $\mathrm{O} 103: \mathrm{H} 2$ & pDEP13 & + & - & 1 & 0 & + & NT & NT & NT \\
\hline $62 \mathrm{R} 70$ & $\mathrm{O} 103: \mathrm{H} 2$ & pDEP12 & + & + & 18 & 15 & + & NT & NT & NT \\
\hline 62 R 75 & $\mathrm{O} 103: \mathrm{H} 2$ & None & + & - & 1 & 2 & + & + & + & + \\
\hline $62 \mathrm{R} 140$ & $\mathrm{O} 103: \mathrm{H} 2$ & pDEP12 & + & + & 16 & 14 & + & NT & NT & NT \\
\hline S102-9 & $\mathrm{O} 5: \mathrm{H}^{-}$ & $59,53,46,35,4 \cdot 4,<4$ & + & + & 41 & 18 & + & NT & NT & $\mathrm{NT}$ \\
\hline $62 \mathrm{R} 15$ & $\mathrm{O} 5: \mathrm{H}^{-}$ & $59,53,35,4 \cdot 4,<4$ & + & - & 22 & 29 & + & NT & NT & NT \\
\hline E1541/68 & O154:H4 & $62,37,13,5$ & - & - & 2 & 3 & - & - & + & - \\
\hline E53181 & $\mathrm{O} 8: \mathrm{H} 9$ & 50 & - & - & 1 & 0 & - & - & + & - \\
\hline
\end{tabular}

NT, Not tested.

* pDEP13, $51 \mathrm{MDa}$; pDEP12, $44 \mathrm{MDa}$. Other plasmids are identified according to their molecular mass; plasmids which hybridize with the CVD419 probe are in bold type.

$\dagger$ Number of cells with 10 or more locally adherent bacteria per 100 cells; all tests were done at least twice.

₹ For a positive test, $10 \%$ or more of 200 cells had 10 or more locally adherent bacteria that were associated with concentrations of fluorescence; all tests were done at least twice. 


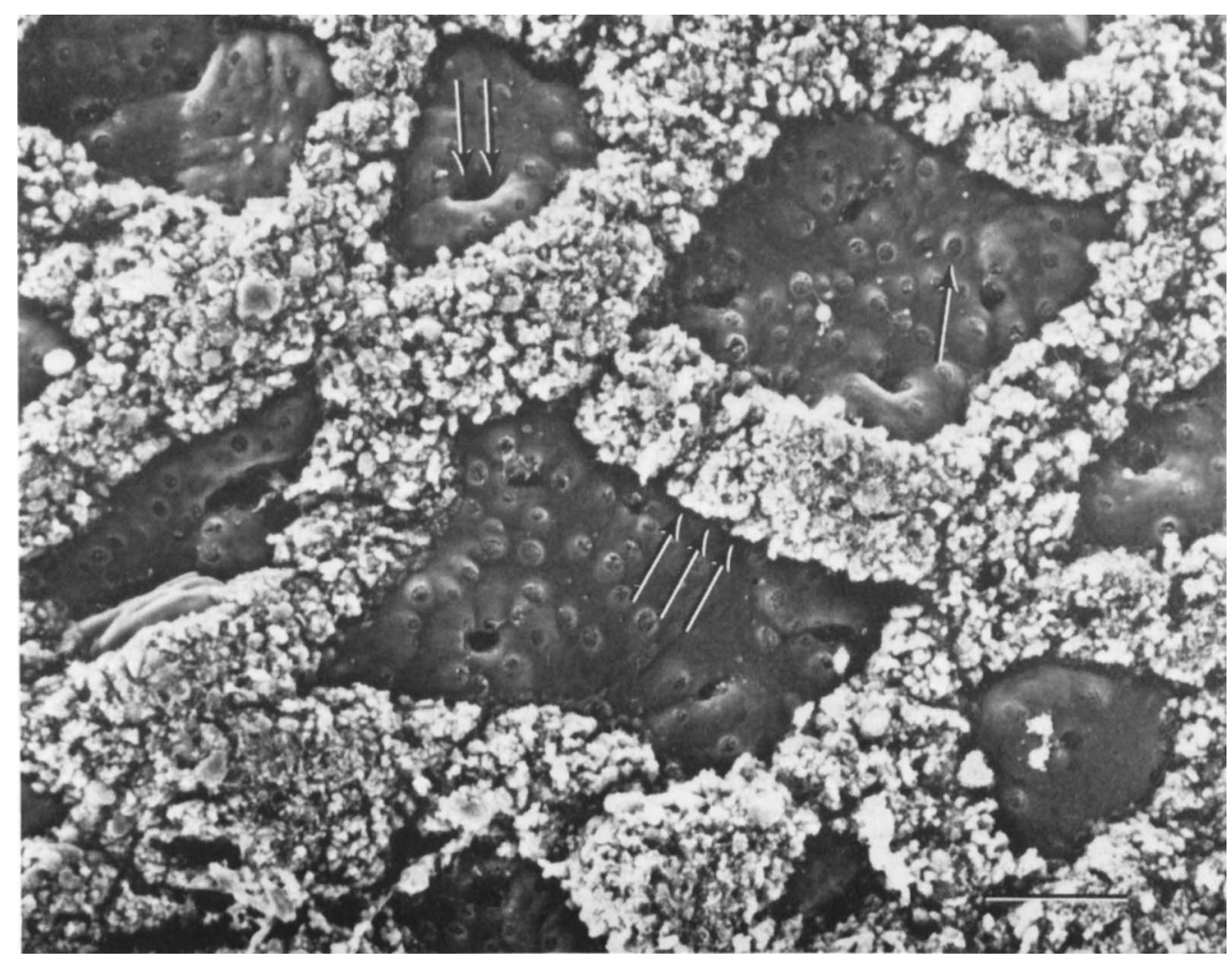

Fig. 1. Scanning electron micrograph of the colonic mucosa of a piglet inoculated with the plasmidless $E$. coli strain $62 \mathrm{R} 75$. The surface is extensively colonized (triple arrows) between crypt orifices (double arrows). Orifices of goblet cells are visible (single arrow). Bar, $50 \mu \mathrm{m}$.

and fourth days after inoculation. The faeces of piglets inoculated with strains E1541 (human commensal) and E53181 (pig commensal) were soft, except that two piglets inoculated with E53181 passed liquid faeces on the third and fourth days after inoculation. One piglet from the first litter, inoculated with S22-1 and contaminated with a Streptococcus sp., collapsed in lateral recumbency and developed paddling movement of all limbs immediately before necropsy. A piglet inoculated with $62 \mathrm{R} 75$ died during the night and was discarded from the study because the intestinal tissues were autolysed.

\section{Gross pathology}

Gross lesions were not detected. Watery contents were noted in the large intestines of piglets inoculated with strain S22-1. In the piglet which collapsed in lateral recumbency prior to necropsy, the renal pelvices were dilated and contained white floccular material and there were yellow foci, $0.5 \mathrm{~mm}$ in diameter, in the renal papillae. The brain and spinal cord of this pig were coloured pale yellow.

\section{Light microscopy}

Lesions were not detected in the kidneys, small intestines or brains of any piglet except that the meninges of the piglet contaminated with a Streptococcus sp., which was found in lateral recumbency prior to necropsy, were infiltrated markedly with neutrophils. Lesions were detected in the livers of eight piglets. These were not correlated with inoculation of any particular strain of $E$. coli because they were detected in at least one piglet from each group. Hepatocytes in the centres of the lobules were swollen, the cytoplasm was rarefied and vacuolated and nuclei were enlarged; increased numbers of hepatocytes in mitosis were detected.

Lesions were detected in the large intestines of all piglets inoculated with strains S22-1 and 62R75 (Table 1); the caecum and ascending and descending colon were always affected but lesions were not always detected in the rectum. Enterocytes located midway between crypt orifices were infected most frequently with bacteria; infection occasionally extended into crypt orifices and rarely to the bottom of crypts. The epithelium was damaged at the sites of infection and enterocytes, many 


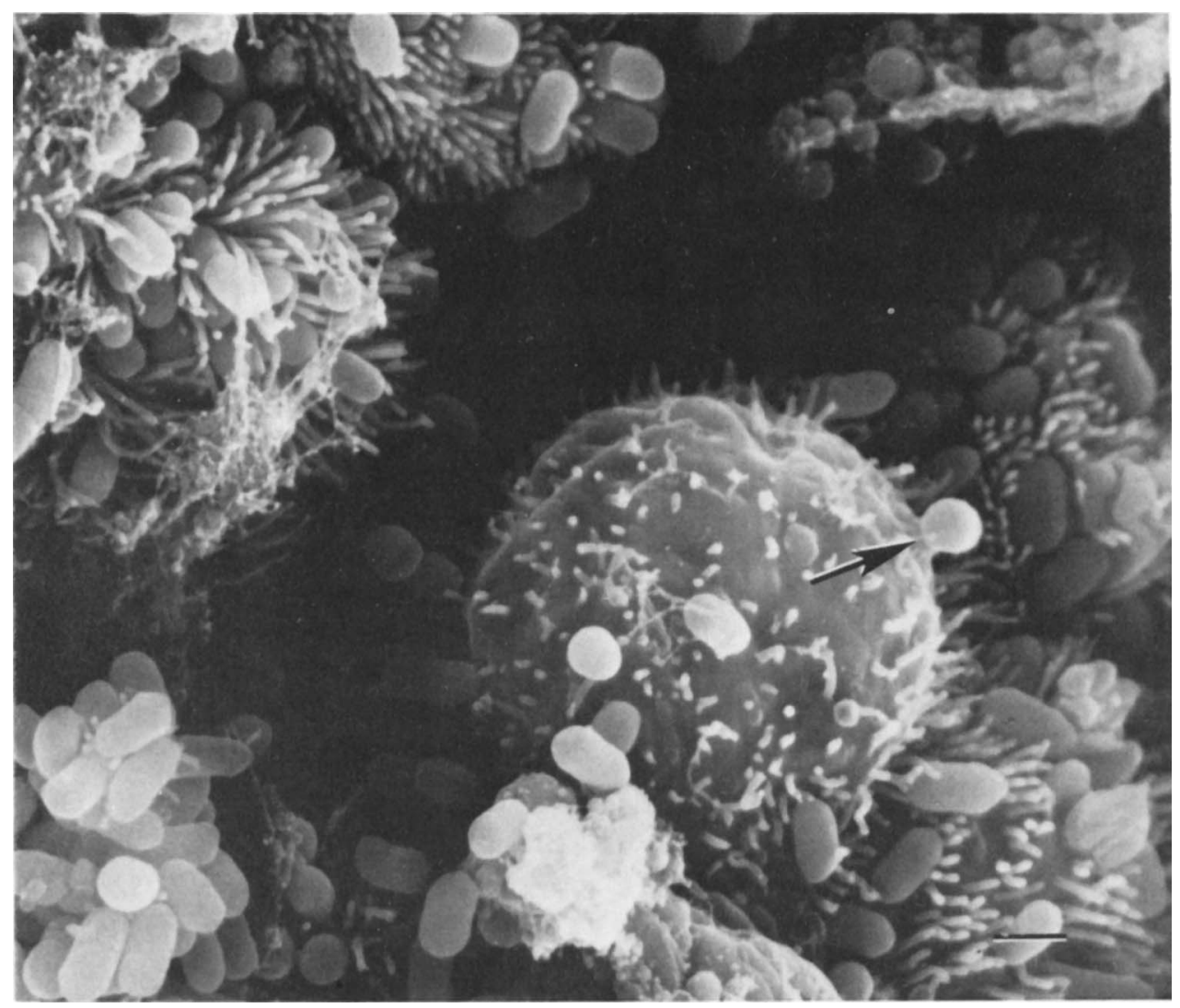

Fig. 2. Scanning electron micrograph of the caecal mucosa of a piglet inoculated with $E$. coli strain S22-1. Microvilli are effaced on infected cells and a bacterium is visible by a pedestal (arrow). Bar, $1 \mu \mathrm{m}$.

which were sloughed, were swollen and contained intracellular lipid; nuclei were irregularly shaped and often swollen. Foci of neutrophil infiltration were seen in the lamina propria and occasionally in the lumen, the neutrophils having apparently emigrated through the epithelium. Lesions were not detected in the large intestines of piglets inoculated with strains E1541/68 and E53181 (Table 1).

\section{Scanning electron microscopy}

Lesions were not seen. in the small intestines of any piglet. They were detected in the large intestines of all piglets inoculated with strains S22-1 and 62R75, but not in piglets inoculated with other strains. The enterocytes located between crypt orifices were infected most frequently (Fig. 1) and abnormal microvilli were seen on these infected cells. Tufts of abnormally long microvilli occurred on some cells whereas they were absent from other cells (Fig. 2). Many enterocytes appeared to be sloughing. Bacteria were often located in depressions on the enterocyte surface and occasionally on cytoplasmic pedestals (Fig. 2).

\section{Transmission electron microscopy}

Transmission electron microscopy of the large intestines of piglets inoculated with strains S22-1 and 62R75 revealed close apposition between bacterial and enterocyte surfaces and effacement of microvilli (Fig. 3); bacteria were frequently located in cup-shaped depressions on the surface but cytoplasmic pedestals were not seen frequently by transmission electron microscopy.

\section{Discussion}

The loss of pDEP12 from strain S22-1 correlated with the reduction in adherence to both HEp-2 cells and to Intestine 407 cells. This plasmid hybridized with the CVD419 DNA probe, so the observation is consistent with the finding of Karch et al. (1987) that curing of a $60 \mathrm{MDa}$ plasmid, which also hybridized with the CVD419 probe, correlated with loss of adherence to Intestine 407 cells.

The other VTEC examined in this study, strain S102-9, did not lose its ability to adhere to HEp-2 cells 


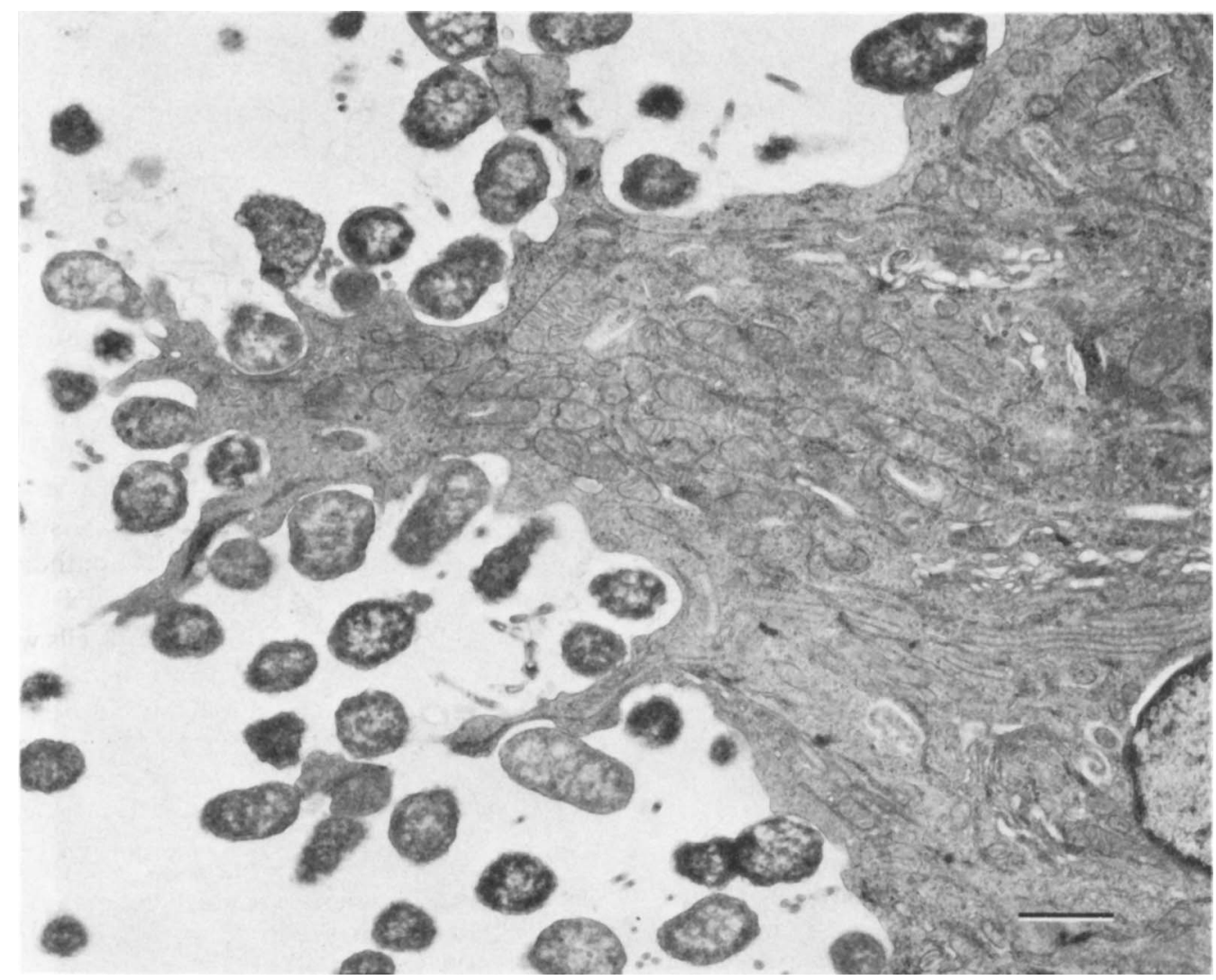

Fig. 3. Transmission electron micrograph of colonic mucosa of a piglet inoculated with $E$. coli strain S22-1. Microvilli are effaced, bacteria are closely associated with the enterocyte surface and the enterocyte cytoplasm is disordered into protrusions to which bacteria are attached. Bar, $1 \mu \mathrm{m}$.

and Intestine 407 cells when it lost the 46 MDa plasmid which hybridized with the CVD419 probe. The inconsistency of these observations, that strain S102-9 does not have adherence-encoding genes on the CVD-419-hybridizing plasmid, indicates that the genetic basis for adherence to epithelial cells in tissue culture for some non-O157:H7 VT-producing $E$. coli may be different from that reported for strains of serotype 0157:H7 (Karch et al., 1987). The inability of serotype O157:H7 strains to adhere to HEp-2 cells (Karch et al., 1987) also differs from observations that VTEC strains of serogroups $\mathrm{O} 5, \mathrm{O} 55, \mathrm{O} 103$ and $\mathrm{O} 111$ have the ability to adhere to both HEp-2 cells and to Intestine 407 cells (Dorn et al., 1989). Future investigations may reveal involvement of outer-membrane proteins, capsule or other cellular components in the adherence mechanisms of VTEC.

Knutton et al. (1989) have proposed that the in vitro FAS test can be used to identify strains of $E$. coli that are able to cause AE lesions in intestinal mucosa. They showed that EPEC and VTEC, for example strains of serogroup O157, were both positive in the FAS test. The two VTEC in the present study, S22-1 and S102-9, were positive in the FAS test and the ability of strain S22-1 to cause AE lesions was confirmed in the gnotobiotic piglet.

Although the FAS test is dependent on initial attachment of a strain to tissue culture cells, Knutton et al. (1989) showed that fluorescence can be clearly demonstrated even when the proportion of cells with localized attaching bacteria is very small. This was confirmed in the present work with derivatives that had reduced attaching ability, due to the loss of a plasmid, but were still positive in the FAS test. Loss of a $60 \mathrm{MDa}$ plasmid, pMAR2, from the enteropathogenic strain E2348/69 also caused a decrease in attachment (Knutton et al., 1987; McConnell et al., 1989) but did not cause a loss of the ability of the strain to cause fluorescence in the FAS test (Knutton et al., 1989). This may indicate another adhesive mechanism where the frequency of occurrence of bacterial and/or cell culture receptors is low in vitro. However, the loss of the plasmid pMAR2 was accompanied by a decrease in the ability to cause diarrhoea in adult volunteers compared to the parent strain E2348/69 (Levine et al., 1985). 
Gnotobiotic piglets inoculated with $E$. coli of serotype O103:H2 (strain S22-1), isolated from a child with diarrhoea, produced liquid faeces, whilst diarrhoea was not seen consistently in piglets inoculated with the plasmidless variant. This may have been the result of studying a small group of piglets, and killing them early in the disease process before diarrhoea developed. It was not due to differences in the ability of the two strains to infect the colon and cause lesions, because both strains colonized the surface of the large intestine equally well and caused lesions identical to AE lesions described previously in piglets inoculated with enterohaemorrhagic E. coli of serotype $\mathrm{O} 157: \mathrm{H} 7$ (Tzipori et al., 1986) and VTEC of other serogroups (Tzipori et al., 1989).

In piglets inoculated with VTEC, the severity of disease and distritgution of infection and lesions was variable (Tzipori et al., 1987, 1989). Infection and lesions were usually absent from the small intestine and extensive in the large intestine, where there was little or no inflammation. EPEC also caused AE lesions but the distribution of infection was slightly different and inflammatory changes more prominent (Tzipori et al., 1989). E. coli which cause AE lesions in gnotobiotic piglets may do so by disrupting and modifying the cytoskeleton and epithelial cell membrane (Knutton et al., 1987) so that bacteria appear to be attached in cupshaped depressions on the enterocyte surface or on cytoplasmic pedestals or more complex cytoplasmic protrusions (Moon et al., 1983; Tzipori et al., 1986; Hall et al., 1988). In this study, bacteria were detected in cupshaped depressions on the enterocyte surface but disruption of the enterocyte surface into pedestals or more complex protrusions was uncommon and seen less frequently than in previous studies of E. coli S102-9 in gnotobiotic calves and piglets (Hall et al., 1985, 1988); the reason for these differences is unclear.

Lesions were detected in the livers of several piglets, but they were not caused by any particular strain because at least one abnormal liver was detected in each experimental group. The cause of the liver lesions was not investigated, but they could have been the result of endotoxin liberated by the large numbers of Gramnegative bacteria in the intestines or because the piglets were exposed to halothane for approximately $30 \mathrm{~min}$ prior to death. One piglet inoculated with strain S22-1 developed clinical signs suggestive of central nervous system pathology and a purulent meningitis was detected post mortem; this piglet had apparently developed streptococcal meningitis immediately prior to necropsy.

The results of inoculating these piglets indicate that the genes encoding for factors involved in the development of AE lesions are located in the chromosome of strain S22-1. The present results, obtained using E. coli of serotype $\mathrm{O} 103: \mathrm{H} 2$, are in agreement with earlier obser- vations of piglets inoculated with $E$. coli of serotype O155:H7 (Tzipori et al., 1987, 1989). These earlier studies, which had shown that a particular $60 \mathrm{MDa}$ plasmid which hybridized with the CVD419 DNA probe was not essential for expression of $\mathrm{AE}$ lesions in gnotobiotic pigs, did not comment on other plasmids which might encode factors involved in the development of AE lesions. The present study confirms that a plasmid which hybridized with the CVD419 DNA probe was not required for production of $\mathrm{AE}$ lesions and shows additionally that the lesions were produced by the plasmid-free derivative.

A comparison of the results of the in vitro adhesion tests with those from inoculating piglets shows that the adhesion test gave no guide to pathogenicity. The derivative of S22-1 which lacked pDEP12 and adhered poorly to HEp- 2 cells or Intestine 407 cells was capable of inducing actin accumulation in vitro, colonizing the porcine large intestine and causing AE lesions.

The authors thank Mr M. J. Dennis for production and care of gnotobiotic pigs, Mrs A. P. Bland for electron microscopy and Mr D. Hawkins for photographs.

C. R.D. was a Fogarty Senior International Fellow at the Division of Enteric Pathogens during the course of this work.

\section{References}

Baldini, M. M., NATARo, J. P. \& KAPER, J. B. (1986). Localization of a determinant for HEp-2 adherence by enteropathogenic Escherichia coli. Infection and Immunity 52, 334-336.

BIRNBoIM, H. C. \& DolY, J. (1979). A rapid alkaline extraction procedure for screening recombinant plasmid DNA. Nucleic Acids Research 7, 1513-1523.

Chanter, N., Morgan, J. H., Bridger, J. C., Hall, G. A. \& ReYNOLDS, D. J. (1984). Dysentery in gnotobiotic calves caused by an atypical Escherichia coli. Veterinary Record 114, 71.

Dorn, C. R., Scotland, S. M., Smith, H. R., Willshaw, G. A. \& Rowe, B. (1989). Properties of Vero cytotoxin-producing Escherichia coli of human and animal origin belonging to serotypes other than O157:H7. Epidemiology and Infection 103, 83-95.

Fontaine, A., Arondel, J. \& Sansett, P. J. (1988). Role of Shiga toxin in the pathogenesis of bacillary dysentery, studied by using a tox ${ }^{-}$ mutant of Shigella dysenteriae 1. Infection and Immunity 56, 3099-3109.

GURWITH, M. J. \& Williams, T. W. (1977). Gastroenteritis in children: a two-year review in Manitoba. I. Etiology. Journal of Infectious Diseases 136, 239-247.

Hall, G. A., Reynolds, D. J., Chanter, N., Morgan, J. H., Parsons, K. R., Debney, T. G., Bland, A. P. \& Bridger, J. C. (1985). Dysentery caused by Escherichia coli (S102-9) in calves: natural and experimental disease. Veterinary Pathology 22, 156-163.

Hall, G. A., Chanter, N. \& Bland, A. P. (1988). Comparison in gnotobiotic pigs of lesions caused by verotoxigenic and nonverotoxigenic Escherichia coli. Veterinary Pathology 25, 205-210.

Karch, H., Heesemann, J., Laufs, R., O'Brien, A. D., Tacket, C. O. \& LeVine, M. M. (1987). A plasmid of enterohaemorrhagic Escherichia coli $\mathrm{O} 157: \mathrm{H} 7$ is required for expression of a new fimbrial antigen and for adhesion to epithelial cells. Infection and Immunity 55, 455-461.

KnUtton, S., Baldini, M. M., Kaper, J. B. \& McNeish, A. S. (1987). Role of plasmid-encoded adherence factors in adhesion of enteropathogenic Escherichia coli to HEp-2 cells. Infection and Immunity 55, $78-85$. 
Knutton, S., Baldwin, T., Williams, P. H. \& MCNeish, A. S. (1989). Actin accumulation at sites of bacterial adhesion to tissue culture cells: basis of a new diagnostic test for enteropathogenic and enterohemorrhagic Escherichia coli. Infection and Immunity 57, 1290-1298.

KonowalchuK, J., SpIERs, J. I. \& Stavric, S. (1977). Vero response to a cytotoxin of Escherichia coli. Infection and Immunity 18, 775779 .

KUSHNER, S. R. (1978). An improved method for transformation of Escherichia coli with ColE1 derived plasmids. In Genetic Engineering, pp. 17-23. Edited by H. W. Boyer \& S. Nicosia. Amsterdam: Elsevier/North-Holland Biomedical Press.

Levine, M. M., Nataro, J. P., Karch, H., Baldini, M. M., KaPer, J. B., Black, R. E., Clements, M. L. \& O'Brien, A. D. (1985). The diarrhoeal response of humans to some classic serotypes of enteropathogenic Escherichia coli is dependent on a plasmid encoding an enteroadhesiveness factor. Journal of Infectious Diseases 152, 550-559.

Levine, M. M., Xu, J.-G., KaPer, J. B., Lior, H., Prado, V., Tall, B., NATARO, J., KaRCH, H. \& WACHSMUTH, K. (1987). A DNA probe to identify enterohemorrhagic Escherichia coli of $0157: \mathrm{H} 7$ and other serotypes that cause hemorrhagic colitis and hemolytic uremic syndrome. Journal of Infectious Diseases 157, 175-182.

MaCkIE, T. J. \& MACCARTNEY, J. E. (1953). Handbook of Practical Bacteriology, 9th edn, p. 181. Edinburgh: Livingstone.

McConnell, M. M., Chart, H., Scotland, S. M., SMith, H. R., WILLSHAW, G. A. \& RoWE, B. (1989). Properties of adherence factor plasmids of enteropathogenic Escherichia coli and the effect of host strain on expression of adherence to HEp-2 cells. Journal of General Microbiology 135, 1123-1134.

Moon, H. W., Whipp, S. C., Argenzio, R. A., Levine, M. M. \& GraNnELLA, R. A. (1983). Attaching and effacing activities of rabbit and human enteropathogenic Escherichia coli in pig and rabbit intestines. Infection and Immunity 41, 1340-1351.

MoXley, R. A. \& Francis, D. H. (1986). Natural and experimental infection with an attaching and effacing strain of Escherichia coli in calves. Infection and Immunity 53, 339-346.

Nataro, J. P., Baldini, M. M., KaPer, J. B., Black, R. E., Bravo, N. \& LEVINE, M. M. (1985). Detection of an adherence factor of enteropathogenic Escherichia coli with a DNA probe. Journal of Infectious Diseases 152, 560-565.

PaI, C. H., Gordon, R., Sims, H. V. \& BRYan, L. E. (1984). Sporadic cases of haemorrhagic colitis associated with Escherichia coli O157:H7. Clinical epidemiologic, and bacterial features. Annals of Internal Medicine 101, 738-742.

Riley, L. W., Remis, R. S., Helgerson, S. D., McGee, H. B., Wells, J. G., Davis, B. R., HeberT, R. J., Olcott, E. S., Johnson, L. M., Hargret,, N. T., Black, P. A. \& Cohen, M. L. (1983). Haemorrhagic colitis associated with a rare Escherichia coli serotype. New England Journal of Medicine 308, 681-685.
Robinson, M. K., Bennett, P. M., Falkow, S. \& Dodd, H. M. (1980). Isolation of a temperature-sensitive derivative of RPI. Plasmid 3, 343-347.

Scatletsky, I. C. A., Silva, M. L. M. \& Trabulsi, L. R. (1984). Distinctive patterns of adherence of enteropathogenic Escherichia coli to HeLa cells. Infection and Immunity 45, 534-536.

Scotland, S. M., Gross, R. J. \& Rowe, B. (1985a). Laboratory tests for enterotoxin production, enteroinvasion and adhesion in diarrhoeagenic Escherichia coli. In The Virulence of Escherichia coli, pp 395-405. Edited by M. Sussman. London: Academic Press.

Scotland, S. M., Smith, H. R. \& Rowe, B. (1985b). Two distinct toxins active on Vero cells are produced by strains of Escherichia coll O157. Lancet ii, 885-886.

Sherman, P., Soni, R., Petric, M. \& Karmali, M. (1987). Surface properties of the Vero cytotoxin-producing Escherichia coli O157:H7. Infection and Immunity 55, 1824-1829.

Smith, H. R., Rowe, B., Gross, R. J., Fry, N. K. \& Scotland, S. M. (1987). Haemorrhagic colitis and Verocytotoxin-producing Escherichia coli in England and Wales. Lancet i, 1062-1065.

SOUTHERN, E. M. (1975). Detection of specific sequences among DNA fragments separated by agarose gel electrophoresis. Journal of Molecular Biology 98, 503-517.

Strockbine, N. A., Marques, L. R. M., Newland, J. W., Smith, H. W., Holmes, R. K. \& O'Brien, A. D. (1986). Two toxinconverting phages from Escherichia coli $\mathrm{O} 157: \mathrm{H} 7$ strain 933 encode antigenically distinct toxins with similar biologic activities. Infection and Immunity 53, 135-140.

Tavernor, W. D., Trexler, P. C., Vaughan, L. C., Cox, J. E. \& JONES, D. G. C. (1971). The production of gnotobiotic piglets and calves by hysterotomy under general anaesthesia. Veterinary Record 88, 10-14.

Tzipori, S., Wachsmuth, K. I., Chapman, C., Birner, R., BrittinghaM, J., JACKSON, C. \& HogG, H. (1986). Studies on the pathogenesis of haemorrhagic colitis caused by Escherichia coll O157 : H7 in gnotobiotic pigs. Journal of Infectious Diseases 154, 712716.

TZIPORI, S., KARCH, H., WaChSMUth, K. I., RobIns-Browne, R. M., O'Brien, A. D., Lior, H., Cohen, M. L., Smithers, J. \& Levine, M. M. (1987). Role of a 60-Megadalton plasmid and Shiga-like toxins in the pathogenesis of infection caused by enterohaemorrhagic Escherichia coli $\mathrm{O} 157: \mathrm{H} 7$ in gnotobiotic piglets. Infection and Immunity 55, 3117-3125.

Tzipori, S., Gibson, R. \& Montanaro, J. (1989). Nature and distribution of mucosal lesions associated with enteropathogenic and enterohaemorrhagic Escherichia coli in piglets and the role of plasmid-mediated factors. Infection and Immunity 57, 1142-1150.

WILlSHAw, G. A., SMITH, H. R. \& ANDERson, E. S. (1979). Application of agarose-gel electrophoresis to the characterization of plasmid DNA in drug-resistant enterobacteria. Journal of General Microbiology 114, 15-25. 